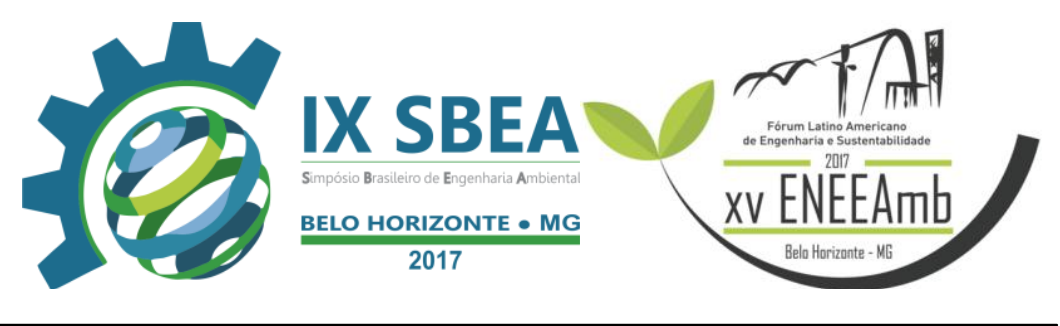

\title{
AVALIAÇÃO DA ÁGUA BRUTA E EFICIÊNCIA DE UMA ETA EM ESCALA REAL
}

Jean Michel Pereira Souza - jean.producao@ hotmail.com

Universidade Federal de Lavras

Arthur Boari - aboari@engambiental.ufla.br

Universidade Federal de Lavras

\section{Daniela Aparecida Vitor}

Universidade Federal de Lavras

Dyego Maradona Ataide de Freitas - dyegofreitas@dma.ufla.br

Universidade Federal de Lavras

Ronaldo Fia - ronaldofia@deg.ufla.br

Universidade Federal de Lavras 


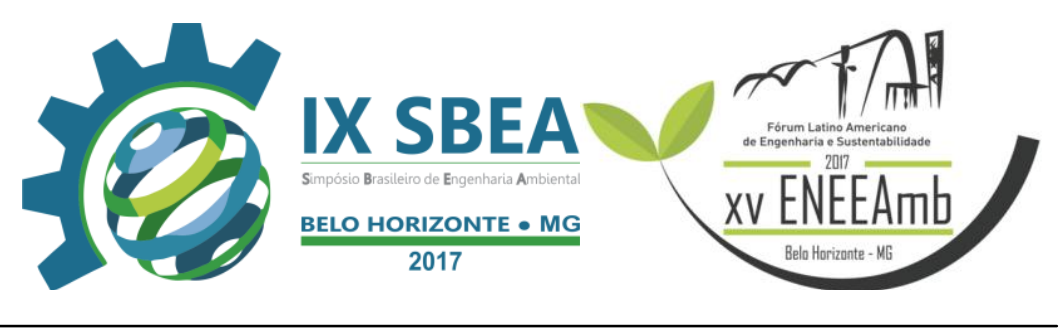

\section{RESUMO}

Para ofertar um bom abastecimento de água, é necessário conhecer a qualidade do corpo d'água de captação, podendo assim dimensionar uma estação de tratamento de água eficiente que poderá fornecer água potável e de boa qualidade. O trabalho teve como objetivo avaliar a qualidade da água bruta, a potabilidade da água tratada e eficiência do tratamento da Estação de Tratamento de Água da UFLA (ETA - UFLA), usando como base a Resolução CONAMA No 357 de 2005 e a Portaria MS No 2914 de 2011. Foram coletadas amostras semanalmente e analisado as variáveis $\mathrm{pH}$, turbidez, cor aparente, cor verdadeira e ferro, entre Janeiro e Março de 2017. A ETA - UFLA atende às recomendações da Resolução CONAMA No 357 para tratamento de água doce e a unidade apresenta ser eficiente atendendo de forma satisfatória ao padrão de potabilidade estabelecido pela Portaria MS Nº 2914.

Palavras-chave: ETA, Água bruta, CONAMA 357.

\section{INTRODUÇÃO/OBJETIVO}

A escolha adequada de um sistema de tratamento de água faz com que a eficiência seja assegurada e garante um controle no excesso de gastos causados por processos de tratamento não necessários, assim como que o mesmo não fique aquém do esperado, já que "a qualidade desejável para uma determinada água é função do seu uso previsto" (VON SPERLING, 2014, p. 14), ou seja, o tratamento tem que estar adequado ao seu uso fim.

Ao planejar uma Estação de Tratamento de Água (ETA), é de suma importância o conhecimento da qualidade do corpo d'água que se deseja fazer a captação, para que a estrutura física e tipo de tratamento da água sejam capazes de ofertar uma água potável. Por esse motivo, é importante correlacionar todos os dados obtidos em amostras da água bruta com as especificações feitas por órgãos ambientais, através da Resolução CONAMA No 357 de 17/03/2005, a fim de definir o melhor sistema de tratamento possível para cada ocasião.

Neste contexto, a avaliação do desempenho de estação de tratamento de água (ETA) se configura como uma ferramenta importante que auxilia o controle operacional 


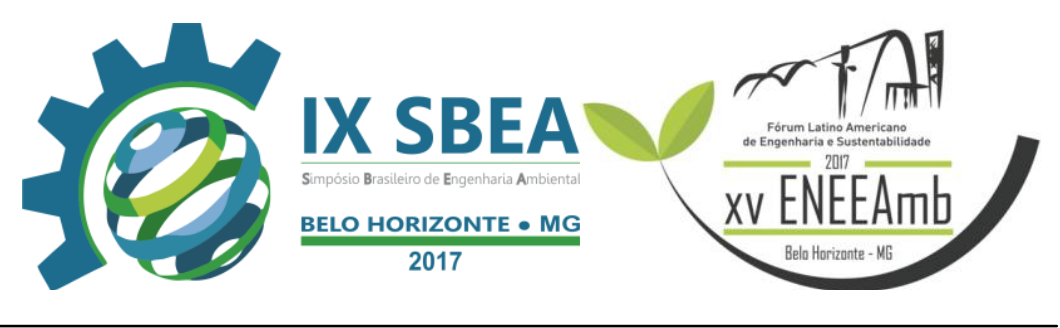

do tratamento, gerando um diagnóstico da situação da ETA operacionalmente e em termos de adequabilidade de parâmetros hidráulicos e de qualidade da água. Esse diagnóstico permite a identificação e, consequentemente, a correção de falhas, caso existam, de forma a melhorar o desempenho, enquadrando os parâmetros de qualidade de água dentro dos recomendados pela Portaria 2914 do Ministério da Saúde.

De acordo com Di Bernardo (1995), as doenças de transmissão hídrica mais comum são febre tifoide e paratifoide, disenteria bacilar e amebiana, cólera, esquistossomose, hepatite infecciosa, giardíase e criptosporidíase. Outras doenças de origem hídrica podem ocorrer, como cáries dentárias por falta de flúor, fluorose por excesso de flúor. Além desses males, danos à saúde humana podem decorrer de sustâncias tóxicas na água.

O tratamento de água é importante para o abastecimento público, pois, previne doenças de veiculação hídrica. Por esse motivo, o Ministério da Saúde estabeleceu na Portaria MS No 2914 de 14/12/2011 o padrão de potabilidade para a água de abastecimento a ser entregue a população.

O seguinte trabalho teve como objetivo avaliar o enquadramento de classe da lagoa de captação segundo a Resolução CONAMA 357, a potabilidade segundo a Portaria MS Nº 2914 e a eficiência de remoção da Estação de Tratamento de Água da Universidade Federal de Lavras (ETA - UFLA).

\section{METODOLOGIA}

O experimento foi realizado na Universidade Federal de Lavras (UFLA) situada no município de Lavras com de Latitude $21^{\circ} 14^{\prime} \mathrm{S}$, Longitude $45^{\circ} 00^{\prime} \mathrm{W}$ e altitude 900 m, no sul de Minas Gerais. Av. Doutor Sylvio Menicucci, 1001 - Kennedy, Lavras MG, 37200-000, onde há uma Estação de Tratamento de Água (ETA). Esta é do tipo convencional, possuindo coagulação, floculação, decantação, filtração e desinfecção.

A água chega à estação através de um conjunto de moto-bomba que está na barragem localizada na universidade.

Foram realizadas coletas de amostras três vezes por semana (salvo feriados e eventos inesperados) entre os meses de janeiro e março de 2017 em dois pontos, sendo um a lagoa de captação e outro na saída da estação de tratamento de água, nomeados 


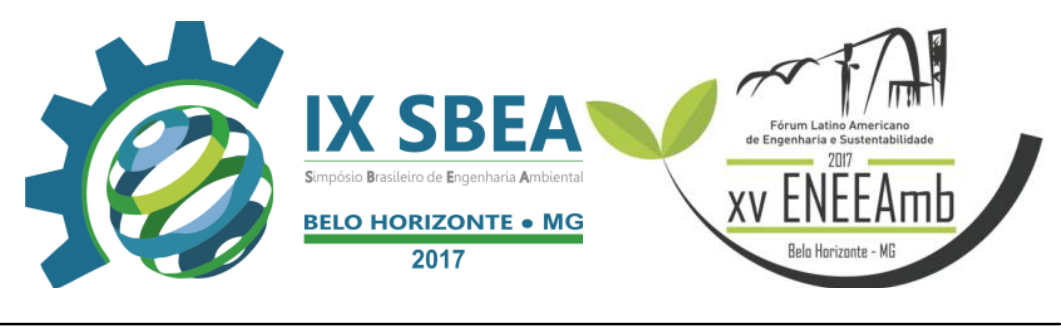

água bruta e água tratada, respectivamente. Durante 75 dias foram analisados as seguintes variáveis: pH (19 vezes) pelo método potenciométrico, turbidez (21 vezes) pelo nefelométrico, cor verdadeira (centrífuga) e aparente (21 vezes) pelo método espectrométrico Tristimulus e ferro (8 vezes) pelo colorimétrico. Os espaços utilizados para as análises foram o Laboratório de Análise de Águas (LAADEG) anexo ao prédio principal do Departamento de Engenharia e prédio do Departamento de Engenharia Ambiental e sanitária.

\section{RESULTADOS E DISCUSSÃO}

As figuras 1, 2, 3 e 4 apresentam em forma de gráfico as variáveis cor verdadeira, turbidez, $\mathrm{pH}$ e ferro para a água bruta e também os valores de enquadramento recomendados pela Resolução CONAMA No 357 de 17/03/2005.

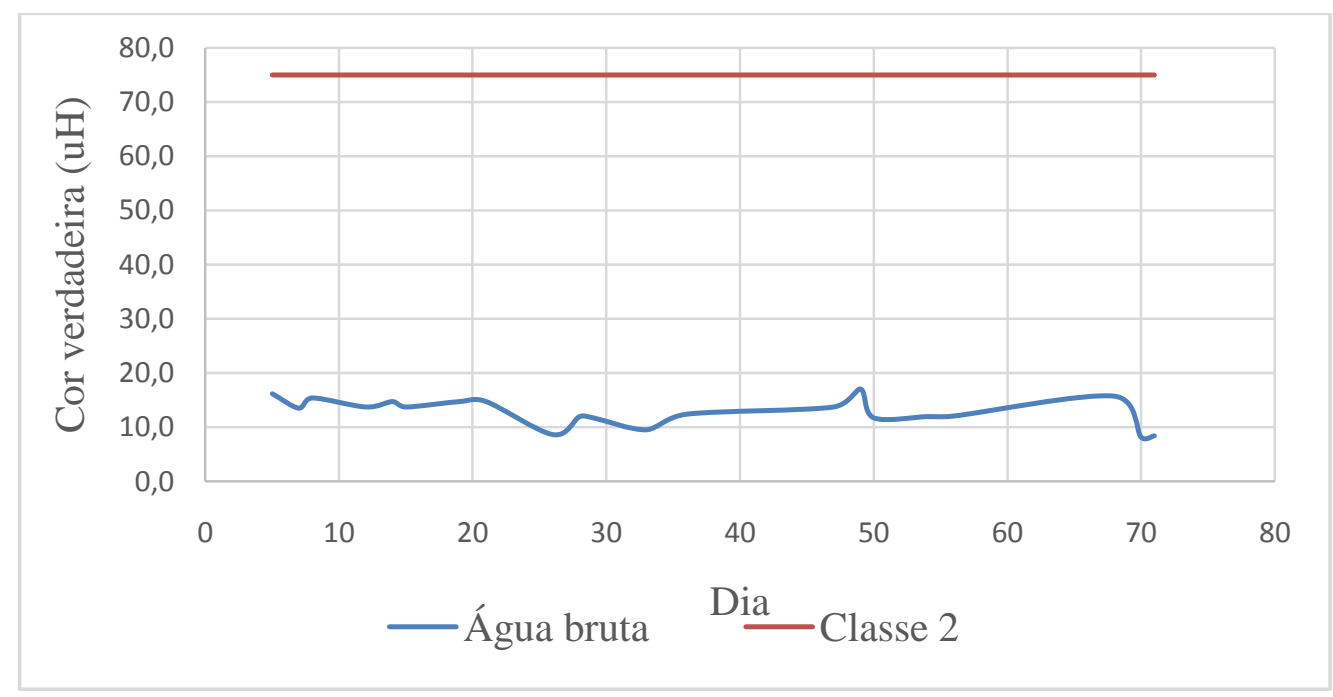

Figura 1: cor verdadeira da água bruta e o valor do parâmetro para enquadramento da resolução CONAMA 357. 

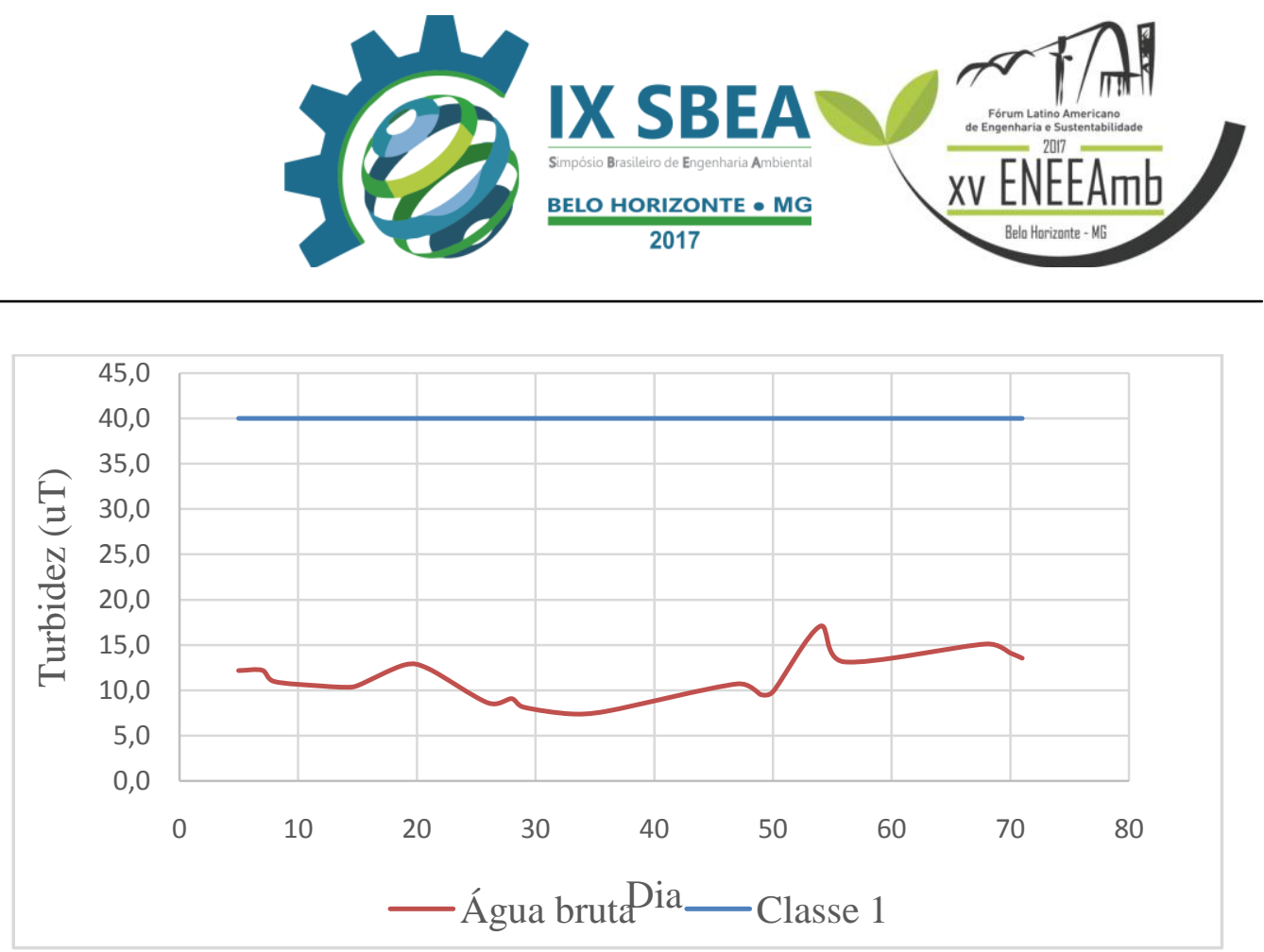

Figura 2: turbidez da água bruta e o valor para enquadramento do parâmetro determinado pela da resolução CONAMA 357.

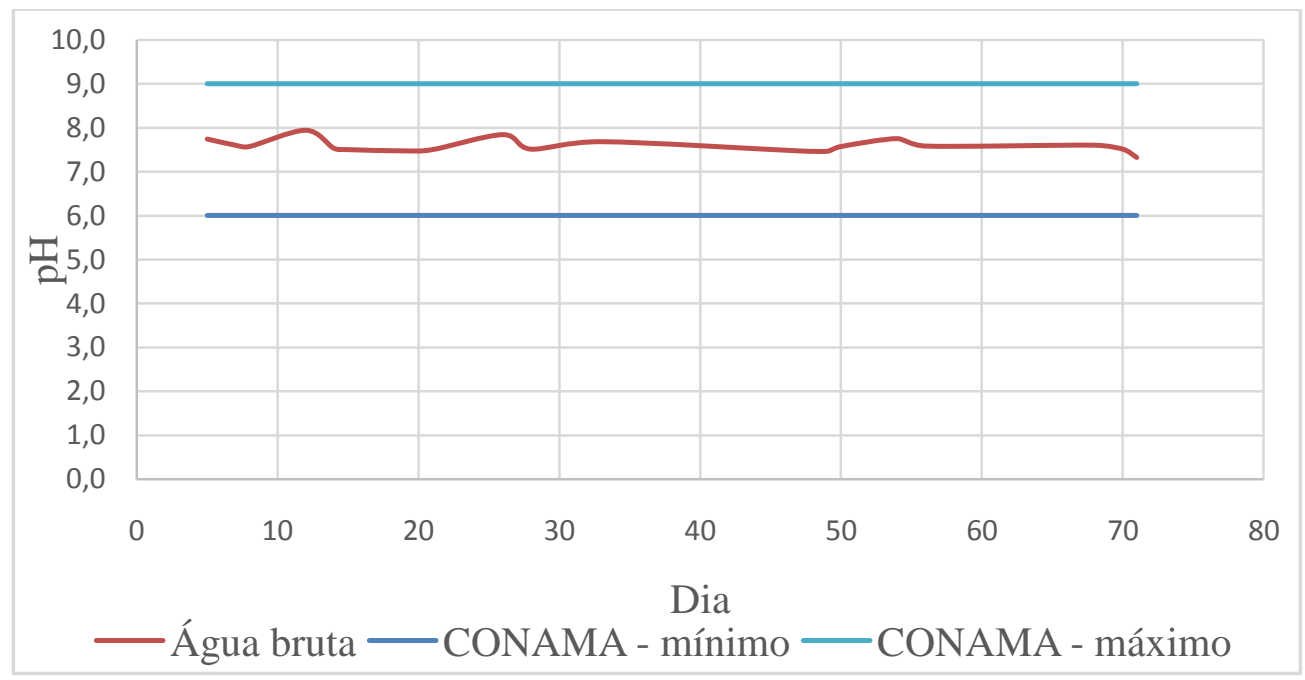

Figura 3: pH da água bruta e o valor para enquadramento do parâmetro determinado pela da resolução CONAMA 357. 

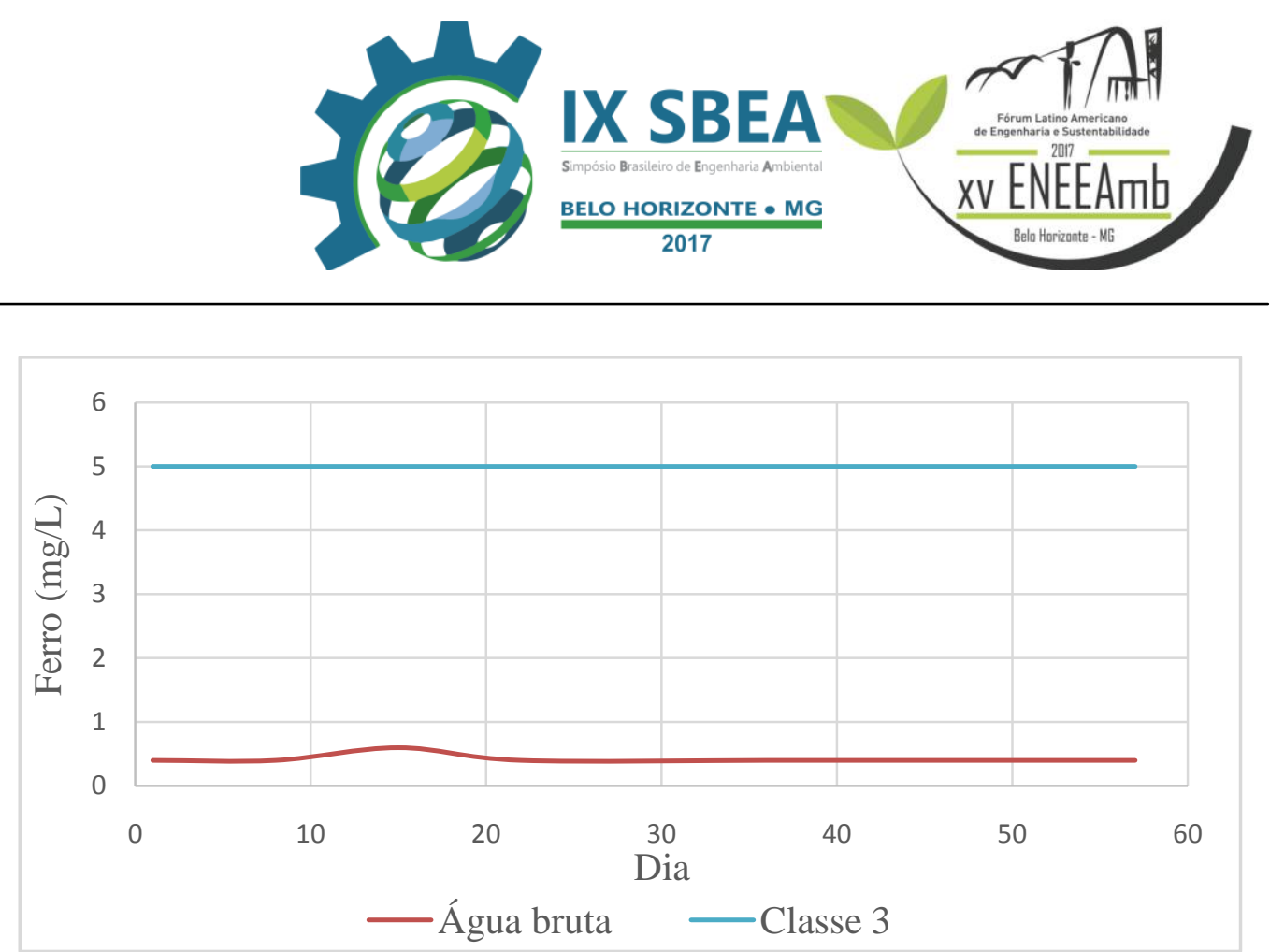

Figura 4: ferro da água bruta e o valor para enquadramento do parâmetro determinado pela resolução CONAMA 357.

Observa-se pelos gráficos que cor verdadeira, turbidez e ferro se enquadram na classe 2 , classe 1 e classe 3 respectivamente, já o $\mathrm{pH}$ se mantém na faixa determinada para todas as classes pela Resolução CONAMA 357.

É possível observar também uma baixa variação em todas as variáveis, o que indica que o corpo hídrico é estável e não há fatores externos que influenciem de forma significativa e que faça com que a água bruta varie a sua qualidade, como mostra a tabela 1 .

Tabela 1: valores médios, máximos e mínimos na lagoa de captação.

\begin{tabular}{cccc}
\hline Variável & Média & Máximo & Mínimo \\
\hline $\begin{array}{c}\text { Turbidez } \\
(\mathrm{uT})\end{array}$ & 11,22 & 17,07 & 7,39 \\
$\begin{array}{c}\text { Cor verdadeira } \\
\text { (1* } \\
(\mathrm{uH})\end{array}$ & 12,84 & 17,03 & 8,20 \\
Ferro $^{8 *}$ & & & \\
$(\mathrm{mg} / \mathrm{L})$ & 0,43 & 0,60 & 0,40 \\
\hline
\end{tabular}

*: Número de análises. 


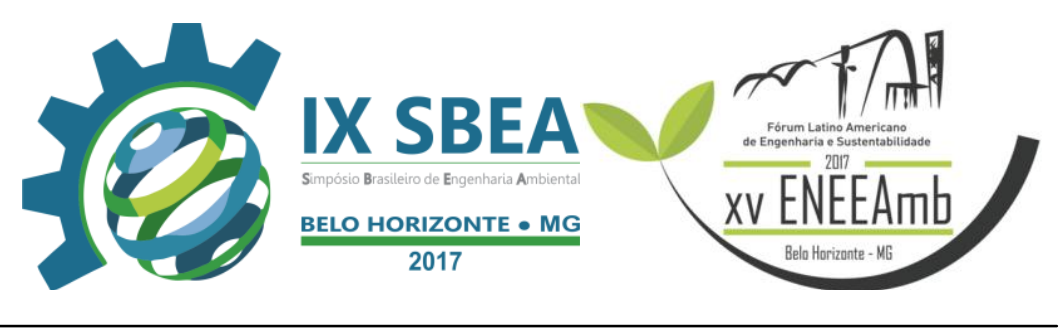

As figuras 5, 6, 7 e 8 apresentam as variáveis cor aparente, turbidez, $\mathrm{pH}$ e ferro da água tratada, além do valor máximo permitido (VMP) estabelecido pela Portaria MS No 2914 pelo Ministério da Saúde.

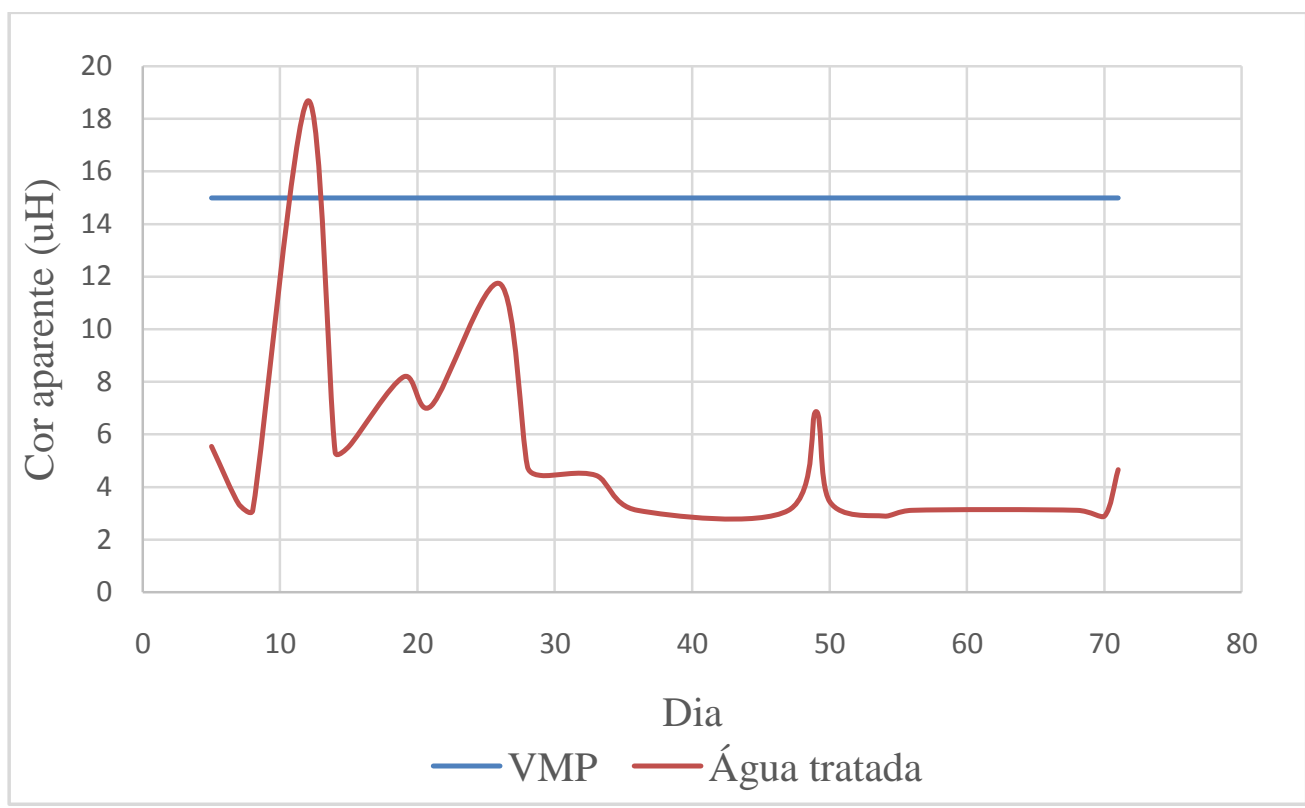

Figura 5: cor aparente da água tratada e o VMP determinado pela Portaria MS $\mathrm{N}^{\circ}$ 2914.

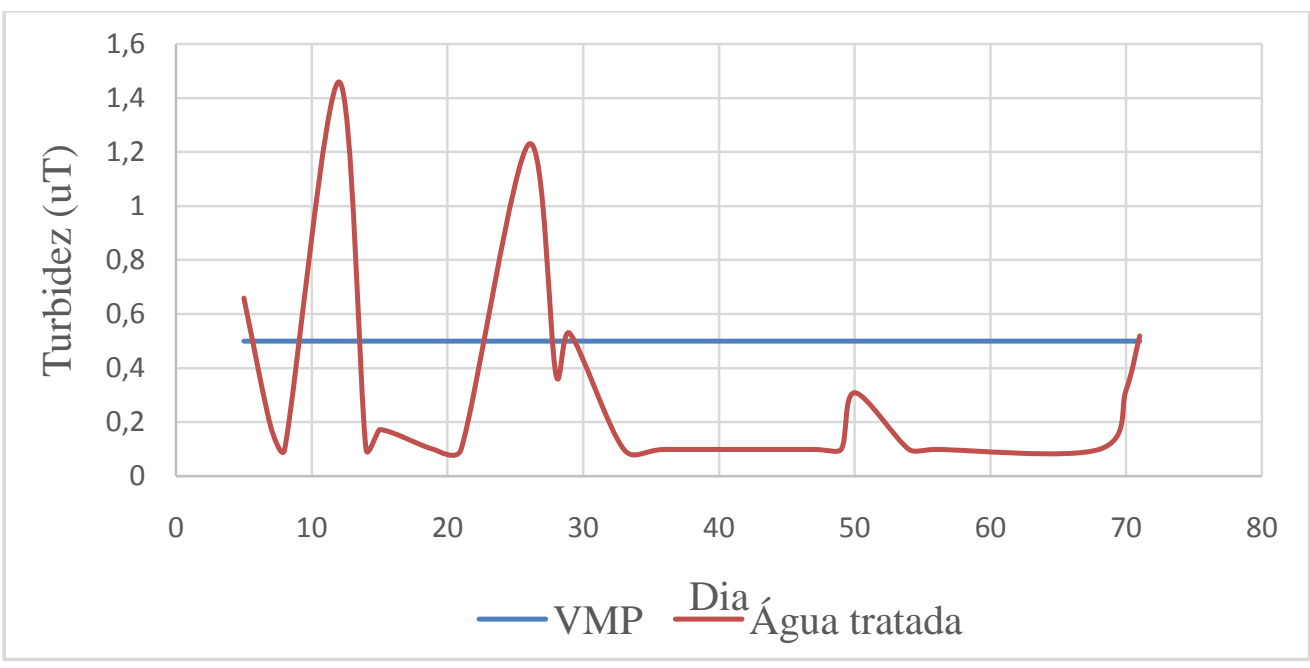

Figura 6: turbidez da água tratada e o VMP determinado pela Portaria MS $\mathrm{N}^{\circ} 2914$. 

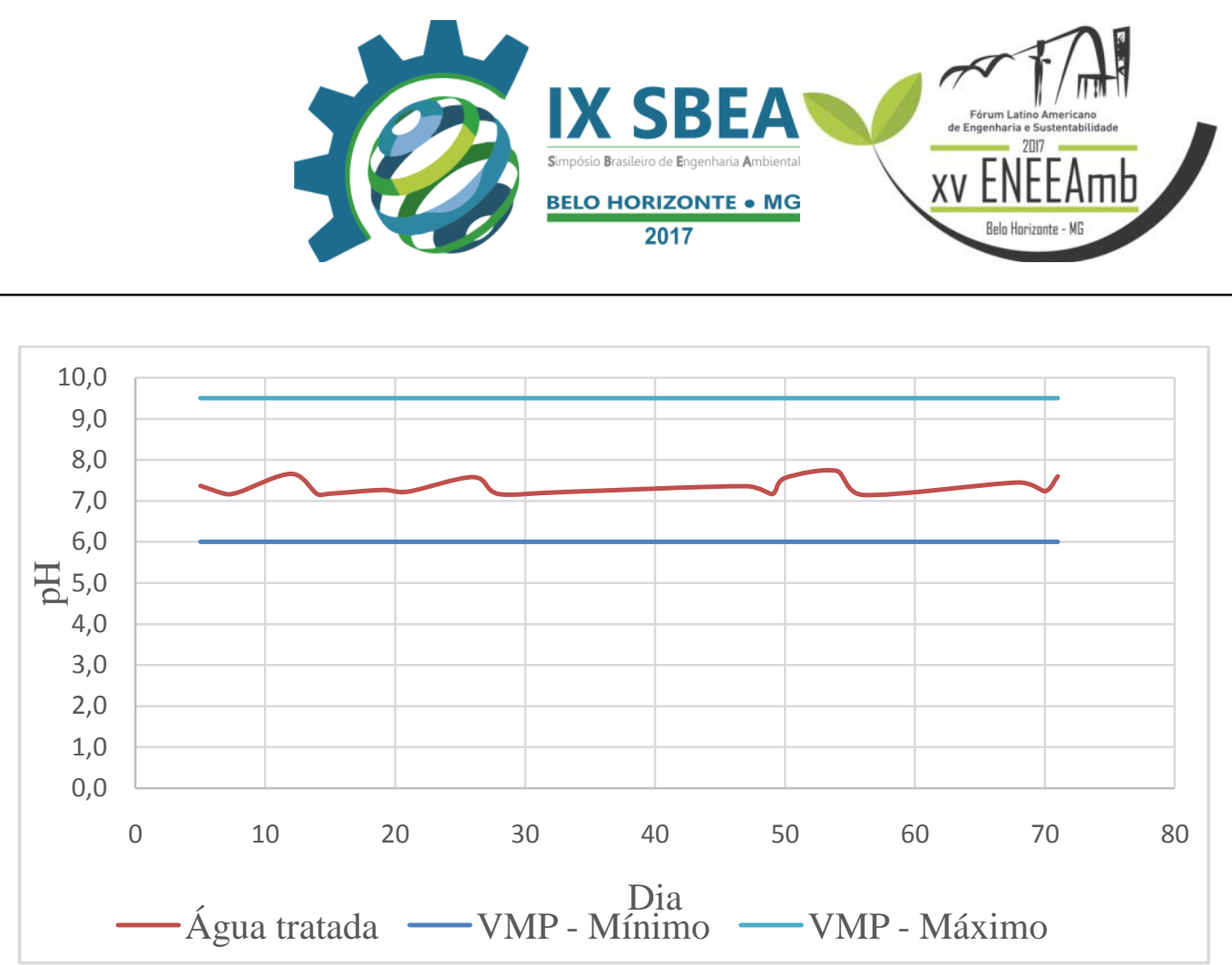

Figura 7: pH da água tratada e o VMP determinado pela Portaria MS Nº 2914.

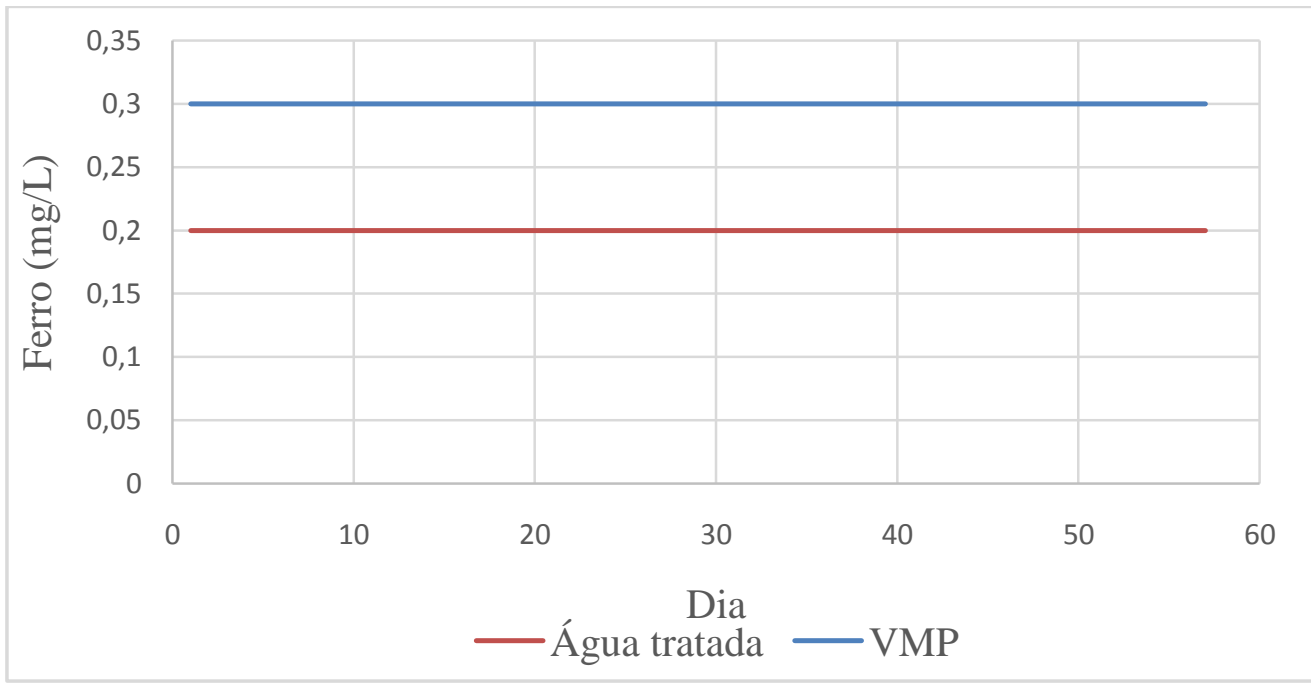

Figura 8: cor aparente água tratada e o VMP determinado pela Portaria MS Nº 2914.

É possível observar após o tratamento que as variáveis $\mathrm{pH}$ e ferro atendem o valor máximo permitido estabelecido pela Portaria 2914 em sua totalidade.

A variável cor aparente se apresentou fora dos padrões estabelecidos em apenas uma das 21 análises, já a turbidez em 3 de 21 análises, ambas atendendo em sua maioria a portaria.

A grande variação na cor aparente e turbidez pode ser associada a dosagem manual de produtos químicos nos registros que interferem diretamente nestas variáveis. 


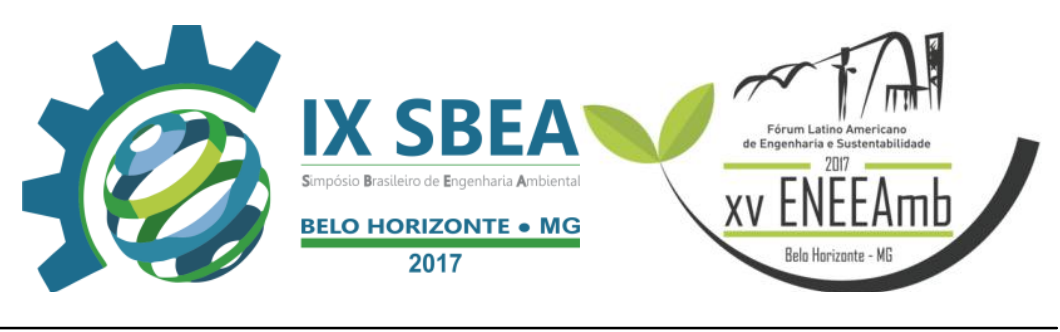

A tabela 2 apresenta os dados avaliados da água tratada em comparação com a portaria 2914.

Tabela 2: valores médios, máximos e mínimos na saída do tratamento.

\begin{tabular}{ccccc}
\hline Variável & Média & Máximo & Mínimo & VMP \\
\hline $\begin{array}{c}\text { Turbidez }^{21^{*}} \\
(\mathrm{uT})\end{array}$ & 0,33 & 1,46 & 0,10 & 0,50 \\
$\begin{array}{c}\text { Cor aparente } \\
\left(\mathrm{l} \text { 1* }^{*}\right.\end{array}$ & 5,50 & 18,69 & 2,90 & 15,00 \\
$\begin{array}{c}\text { Ferro } \\
8^{*}\end{array}$ & 0,20 & 0,20 & 0,20 & 0,30 \\
$(\mathrm{mg} / \mathrm{L})$ & & & & \\
\hline
\end{tabular}

*: Número de análises.

Os resultados das analises da eficiência média da ETA - UFLA na remoção da cor aparente, cor verdadeira, ferro e turbidez. são demonstrados na tabela 3 .

Tabela 3: valores médios de eficiência de remoção.

\begin{tabular}{cccc}
\hline Variável & Entrada & Saída & Eficiência (\%) \\
\hline $\begin{array}{c}\text { Turbidez } \\
(\mathrm{uT})\end{array}$ & 11,22 & 0,33 & 97,09 \\
$\begin{array}{c}\text { Cor verdadeira }{ }^{21^{*}} \\
(\mathrm{uH})\end{array}$ & 12,84 & 3,16 & 75,40 \\
$\begin{array}{c}\text { Cor aparente } \\
(\mathrm{uH})\end{array}$ & 35,82 & 7,44 & 79,22 \\
Ferro & & & \\
$(\mathrm{mg} / \mathrm{L})$ & 0,43 & 0,20 & 53,48 \\
& & \\
\hline
\end{tabular}




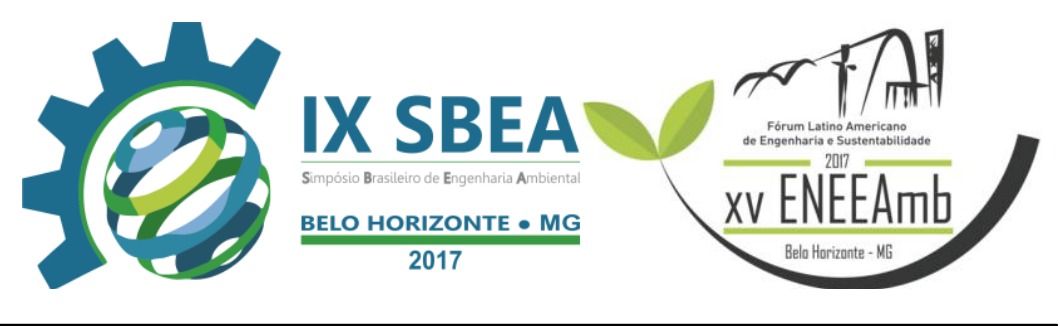

É possível observar uma variação nas eficiências médias comparando todas as variáveis da tabela 3. Destaca-se a turbidez e ferro por apresentarem a maior $(97,09 \%)$ e menor $(52,94)$ eficiência média de remoção respectivamente.

\section{CONCLUSÕES/RECOMENDAÇÕES}

Os resultados mostram que a água bruta utilizada para tratamento varia o seu enquadramento em classe 2 e 3. Para essas classes de corpos d'água a Resolução CONAMA N 357 indica um tratamento convencional ou avançado (se necessário) para posterior consumo humano, o qual, a UFLA possui, por isso concluímos que a ETA/UFLA atende o que foi especificado na resolução CONAMA.

Avaliando a água tratada, é possível concluir que o tratamento é satisfatório e na maioria das vezes atendeu ao especificado pela Portaria MS $\mathrm{N}^{\circ} 2914$, isso demonstra que as recomendações da Resolução CONAMA N 357 tem sentido e pode ser utilizado como base no planejamento para uma unidade de tratamento de água que atenda o padrão de potabilidade.

\section{REFERÊNCIAS BIBLIOGRÁFICAS}

American Public Health Association / American Water Works Association / Water Environment Federation. Standard methods for the examination of water and wastewater. 21st ed. Washington, 2005.

Brasil. (2005) Resolução CONAMA n 357, de 17 de março de 2005. Dispõe sobre a classificação dos corpos de água e diretrizes ambientais para o seu enquadramento, bem como estabelece as condições e padrões de lançamento de efluentes, e dá outras providências. Diário Oficial da União, Brasília, DF, 18 mar. 2005.

Di Bernardo, L. Alga e suas Influências na Qualidade das Águas e nas Tecnologias de Tratamento. Rio de Janeiro, ABES.1995. 128 p. 


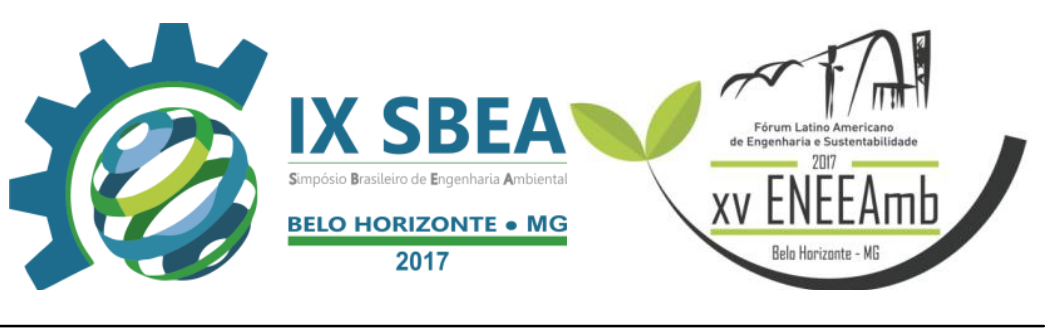

Ministério da Saúde. Portaria no 2.914, de 12 de dezembro de 2011. Dispõe sobre os procedimentos de controle e de vigilância da qualidade da água para consumo humano e seu padrão de potabilidade. Diário Oficial da União, Brasília, DF, 12 dez. 2011.

VON SPERLING, Marcos. Introdução à qualidade das águas e ao tratamento de esgotos, $4^{\text {a }}$ ed. Belo Horizonte: Ed. UFMG, 2014, 470 p. 